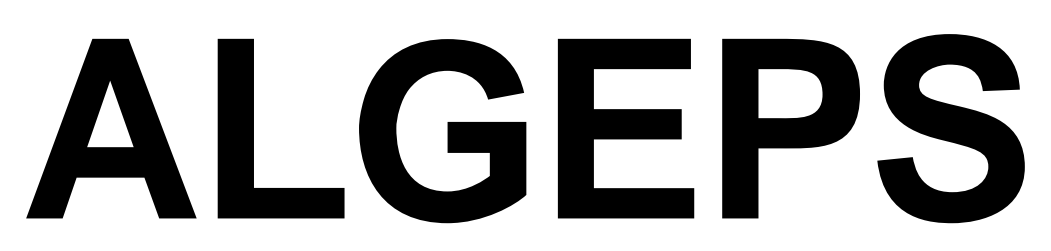

REVISTA DE GEOLOGIA, SÈRIE B no 584 - Març del 2012

ISSN $1132-7014$

D.L.B. 28.178 - 92

14 pàgines

\begin{abstract}
RECORRIDO DESDE ALTORRICÓN A TAMARITE DE LITERA, ALCAMPEL, BAELLS y NACHÁ, A TRAVÉS DEL PATRIMONIO GEOLÓGICO Y MINERO DE LAS COMARCA DE LA LITERA
\end{abstract}

Josep M. Mata-Perelló

Aquest recorregut va ésser experimentat amb docents el dia 6 DE JUNY DEL 2010 


\section{RECORRIDO DESDE ALTORRICÓN A TAMARITE DE LITERA, ALCAMPEL, BAELLS y NACHÁ, A TRAVÉS DEL PATRIMONIO GEOLÓGICO Y MINERO DE LAS COMARCA DE LA LITERA}

\section{ADVERTENCIAS PREVIAS}

Como en otros recorridos de RECONOCIMIENTO GEOLÓGICO (o de RECONOCIMIENTO GEOLÓGICO Y MINERO), el recorrido se compondrá de diversas PARADAS. En este caso serán seis.

Por otra parte, habrá que tener en cuenta, en todo momento, especialmente antes de empezar los recorridos de los diferentes tramos, el estado de los caminos y carreteras, por donde transitará el recorrido. Al respecto, cabe decir que prácticamente todos estos tramos se halla en buenas condiciones.

Finalmente, como ya hacemos en otros recorridos similares, queremos decir que hace falta tener un cuidado muy especial en el respeto a la naturaleza, a lo largo de todo el recorrido del itinerario, y también fuera de él.

\section{BREVE INTRODUCCIÓN GEOLÓGICA}

Como en el caso del ITINERARIO GEOLÓGICO DE BINEFAR A ALINS, el recorrido de este itinerario, se desarrollará exclusivamente por la Depresión Geológica del Ebro (en sus tramos iniciales y centrales, desde Altorricón a las inmediaciones de Nachá) y por los Pirineos, (en los tramos finales del recorrido, dentro del municipio de Baells, en Nachá).

Así, a lo largo de todo de todo el primer tramo del recorrido del itinerario (dentro de la Depresión Geológica del Ebro) se irán encontrando inicialmente afloramientos cenozoicos, en su mayoría de carácter arcilloso, yesoso y calcolutítico, pertenecientes al Oligoceno.

Luego, ya dentro del recorrido por los Pirineos, se Irán encontrando afloramientos triásicos del Keuper (con niveles arcillosos y yesosos). Asimismo, encontraremos también afloramientos de los materiales carbonatados del Cretácico, dentro de los afloramientos pirenaicos de las Sierras Marginales, en el denominado Pirineo Meridional.

Asimismo, a menudo, encontraremos afloramientos de los materiales detríticos cuaternarios, por encima de los anteriores 


\section{BREVE INTRODUCCIÓN GEOGRÁFICA}

En este caso, el recorrido del presente itinerario se efectuará exclusivamente por una comarca aragonesa, la de la Litera / Llitera. Así, se iniciará en la población de Altorricón, para dirigirse luego hacía el Norte, yendo rápidamente hacía Tamarite de Litera (la capital cultural de la comarca). El recorrido terminará en la población de Nachá, dentro del municipio de Baells.

En este recorrido, se circulará por los términos municipales de: Altorricón, Tamarite de Litera, Alcampell y Baells, todos ellos de la comarca de la Litera / Llitera, en donde se habrá iniciado el recorrido.

Esta comarca, gravita en torno a dos ríos de la misma cuenca: el Noguera Ribagorzana que drena los sectores orientales y el Cinca que hace lo propio con los sectores occidentales. En cuanto al recorrido del itinerario, circulará íntegramente por los primeros sectores.

\section{OBJETIVOS GENERALES DE ESTE ITINERARIO}

En este itinerario, los objetivos generales que se han de conseguir, se pueden concretar en los siguientes aspectos:

1.- Estudio y reconocimiento de los materiales cenozoicos (en buena parte del Oligoceno y del Mioceno, según los lugares) situados en la Depresión Geológica del Ebro, que iremos encontrando a lo largo del recorrido del itinerario, entre las inmediaciones de Altorricón, Tamarite de Litera, Alcampell y Baells.

2.- Visión de algunas de las antiguas explotaciones encontradas a lo largo del recorrido del itinerario. En concreto de:

2A) de diversas explotaciones de yeso, situadas en el municipio de Tamarite de Litera, entre los afloramientos cenozoicos, aunque solo se parará en una de ellas.

2B) de alguna de las explotaciones de materiales carbonatados mesozoicos, que veremos en Nachá.

2C) de una antigua explotación de una mineralización manganesífera de relleno de cavidades kársticas, situada entre los materiales carbonatados mesozoicos, que veremos en Nachá.

3.- Observación del impacto producido por las actividades mineras. I si se da el caso, de las restauraciones realizadas para paliar este impacto.

4.- Visión de los diferentes lugares directamente relacionados con el Patrimonio Geológico y Minero que iremos encontrando a lo largo del recorrido del presente itinerario. Dentro del primero, veremos las bolsadas manganesíferas de Nachá, así como el Castillot de Baells y a la laguna endorreica del Estany de Queraltó, cercano a Tamarite de Litera. Y dentro del segundo nos referimos al Horno de Tejas de Tamarite de Litera y al Horno de Yeso, también de Tamarite de Litera. 


\section{ANTECEDENTES BIBLIOGRÁFICOS}

En relación con este itinerario, no conocemos ningún antecedente, relativo a otro itinerario que discurra por este lugar. En este sentido, este itinerario ya constituye un antecedente, si no estamos equivocados. Existen antecedentes en itinerarios cercanos nuestros: MATA - PERELLÓ (1990, 1991, 1996 t 2002); así como en MATA PERELLÓ y MONTANÉ GARCÍA (2002 y 2004). Aunque se trata de recorridos no coincidentes con el que ahora presentamos.

Por otra parte, haremos mención de algunos trabajos, de carácter geológico generalista, que corresponden a los trabajos del IGME (1972, 1974 y 1975), relativos al Mapa Geológico de España (a Escala 1.200.000), al Mapa Metalogenético de España y al Mapa de Rocas Industriales de España También cabe mencionar a GUIMERÁ et altri (1992), así como a RIBA et altri (1976).

Con respecto a las mineralizaciones que iremos encontrando, mencionaremos los trabajos de: CALVO et altri (1988); MAESTRE (1845); así como nuestros trabajos: MATA-PERELLÓ (1987 y 1998).

También mencionaremos el trabajo de PRAMES (2005) dedicado a la comarca del Campo de Belchite. Así como el del GOBIERNO DE ARAGÓN (2001), dedicado a los Puntos de Interés Geológico de Aragón.

Finalmente, diremos que todos estos trabajos (así como otros que ahora no hemos aludido), figurarán mencionados, por orden alfabético, en el apartado dedicado a las REFERENCIAS BIBLIOGRÁFICAS.

\section{RECORRIDO DEL ITINERARIO}

Este recorrido se iniciará en las inmediaciones de la población de Altorricón, desde donde se dirigirá inmediatamente, sin efectuar ninguna parada, hasta Tamarite de Litera (la capital cultural comarcal), en donde se realizaran diversas paradas, en las cercanías de la población. Tras ello, el recorrido se dirigirá hacia Alcampell y de ahí a Baells. En esta población se realizará una nueva parada. Tras ello, el recorrido se dirigirá hacía Nachá, en donde se efectuaran las últimas paradas del itinerario.

\section{DESCRIPCIÓN DEL ITINERARIO}

Como de costumbre, haremos una serio de PARADAS (o ESTACIONES), en donde se realizaran diversas explicaciones en torno a las características del lugar en donde se halla la PARADA. Por otra parte, en ellas haremos mención del término municipal dónde se encuentran, así como del número del "Mapa Topográfico Nacional (a escala 1:50.000, que indicaremos entre paréntesis. Así, ahora (en este recorrido) utilizaremos solamente tres hojas, concretamente las siguientes: 326 (o de Monzón), 327 (o de Os de Balaguer) y $\mathbf{3 5 8}$ (o de Almacelles). Sin embargo, en la última no efectuaremos ninguna parada, a excepción de la primera, una parada condicional. Así, la relación ordenada de las paradas que constituyen el recorrido de este itinerario, es la siguiente: 
PARADA 1 - CONDICIONAL. ANTIGUO TEJAR DE ALTORRICÓN, (término de Altorricón, comarca de la Litera / Llitera). (Hoja 326).

El recorrido del presente itinerario lo iniciaremos en la localidad de Altorricón (la más meridional de la comarca de la Litera / Llitera). Y concretamente lo iniciaremos frente al lugar en donde estaba situado un antiguo tejar.

Este lugar (y todo el término municipal de Altorricón) se halla situado en la Depresión Geológica del Ebro, entre afloramientos de los materiales cenozoicos (del tránsito del Oligoceno al Mioceno) que la rellenan. Estos materiales son eminentemente arcillosos y calcolutíticos, de tonalidades ocres.

PARADA 2. TEJERÍA, (término municipal de Tamarite de Litera, comarca de la Litera / Llitera). (Hoja 326).

Después de realizar la parada anterior, conviene efectuar un recorrido hasta el cercano pueblo de Tamarite de Litera, situado a unos $8 \mathrm{Km}$. Allí efectuaremos un breve recorrido de menos de $2 \mathrm{Km}$, por la carretera de Albelda. Al llegar al lugar en donde quedan los restos de un horno de tejas (a la izquierda), haremos una nueva parada, a unos $10 \mathrm{Km}$ de la anterior.

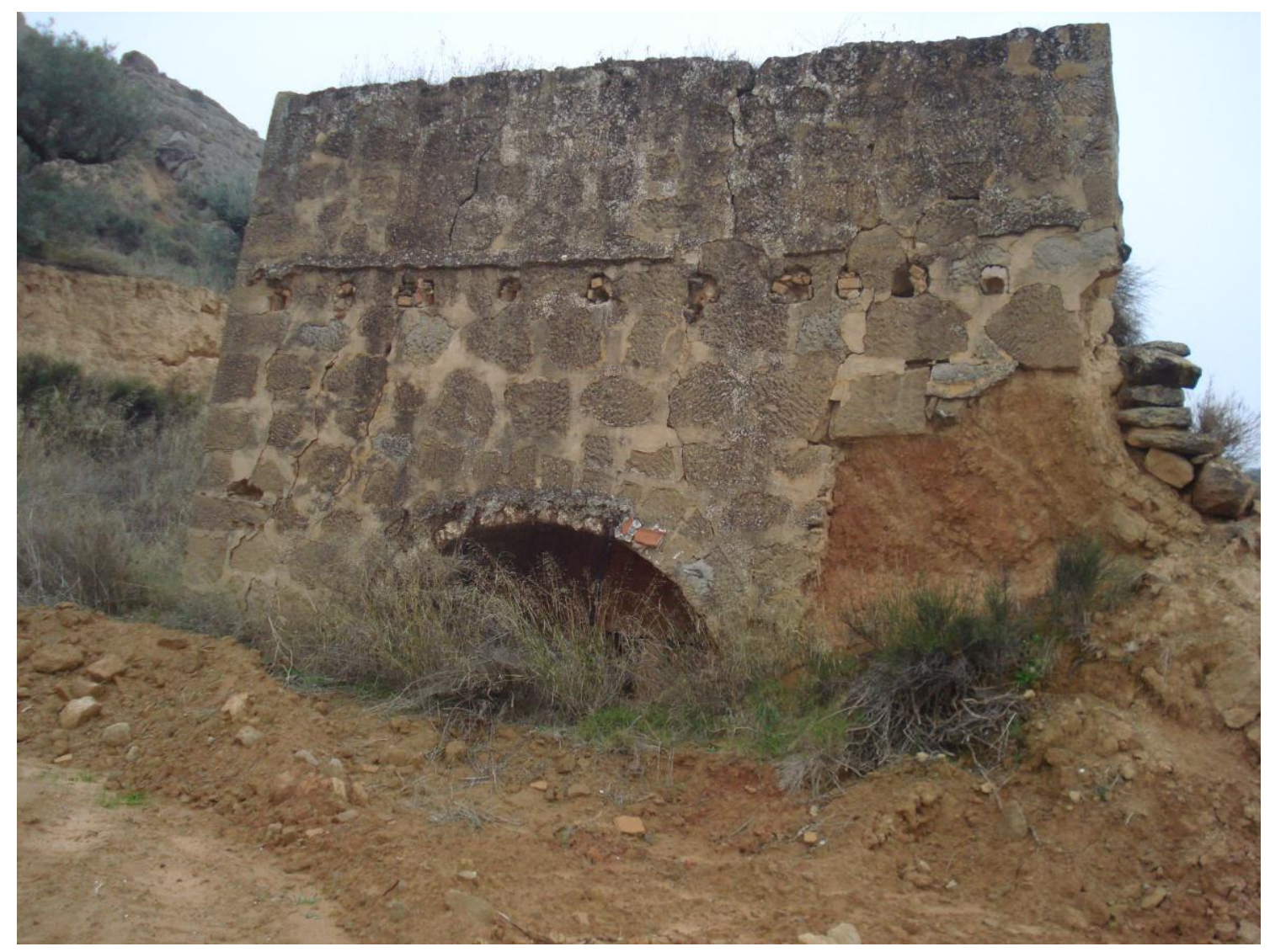

Horno de Tejas 
En este recorrido, hemos ido encontrando afloramientos de los materiales que rellenan la Depresión Geológica del Ebro; concretamente los materiales cenozoicos del Oligoceno en tránsito al Mioceno. Estos son los materiales que aparecen en el lugar de la parada. Aquí, antaño se habían explotado las arcillas y las calcolutitas, como materia prima para la tejería.

En relación con el Horno de Tejas de la Tejería, conviene decir que es un importante elemento del Patrimonio Minero de la Litera.

PARADA 3. HORNO DE YESO y YESERA (término municipal de Tamarite de Litera, comarca de la Litera / Llitera). (Hoja 326).

Después de realizar la parada anterior, conviene retornar al pueblo, atravesándolo y saliendo por la carretera de Alcampell. Justo a la salida de Tamarite (a la izquierda de la carretera) se encuentra una antigua yesera (explotación de yeso) y junto a ella los restos de una yesería (fábrica de yeso). Ahí efectuaremos una nueva parada, a unos $3 \mathrm{Km}$ de la anterior.

En este recorrido, hemos encontrado en principio los materiales citados en la parada anterior. Sin embargo, al atravesar el pueblo y al llegar al lugar de la parada, se han hecho evidentes unos tramos cenozoicos yesosos (Formación Barbastro). Se trata de alternancias de calcolutitas yesosas y de yesos. Precisamente, estos han sido los materiales antaño explotados en este lugar, en la antigua yesera.

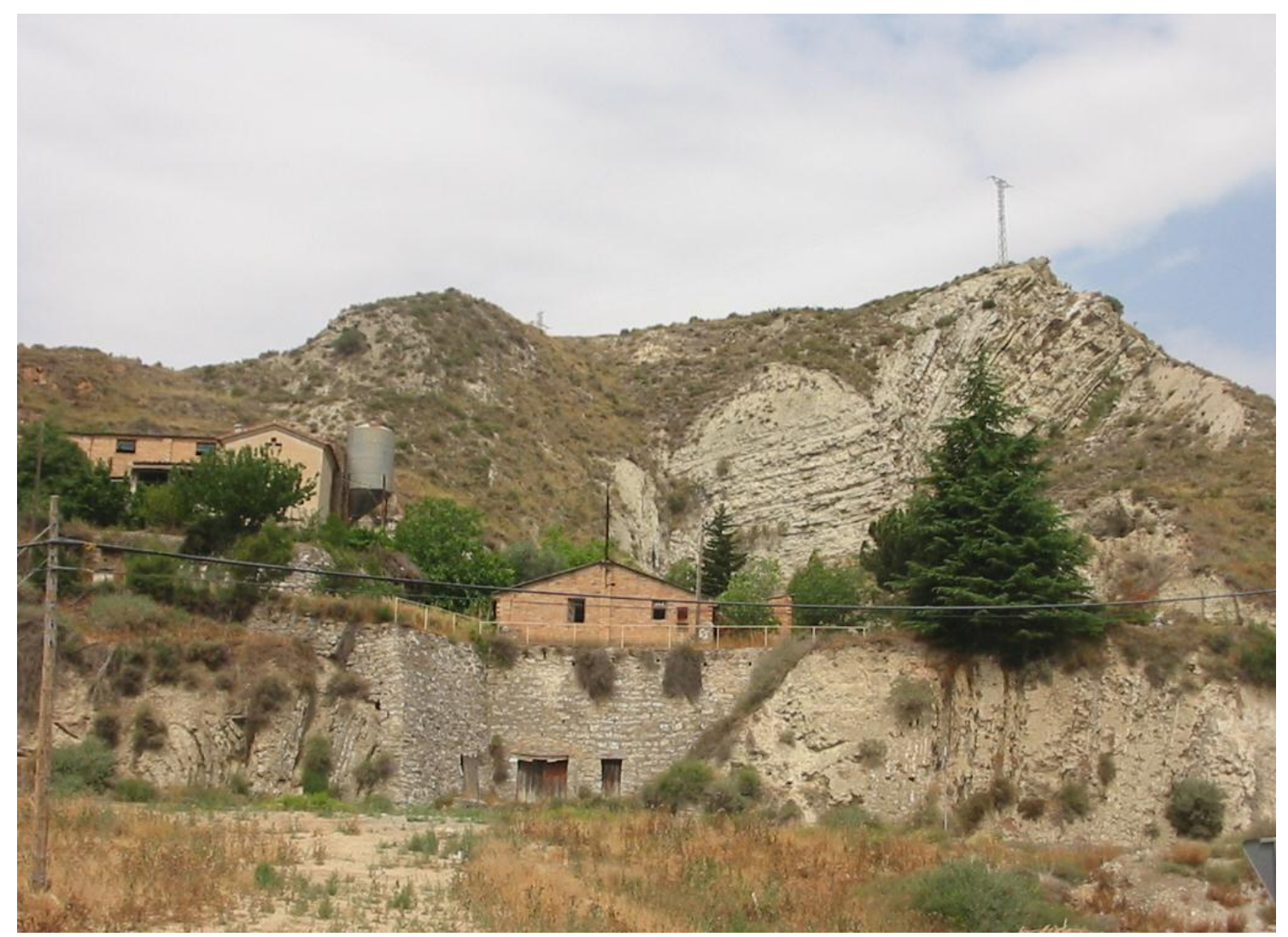

La yesera y la yesería 
Como en el caso anterior, estos elementos (fundamentalmente el Horno de Yeso de la antigua Yesería) son elementos importantes del Patrimonio Minero de la comarca de la Litera.

\section{PARADA 4. ESTANY DE QUERALTÓ, (término municipal de Tamarite de Litera, comarca de la Litera / Llitera). (Hoja 326).}

Después de realizar la parada anterior, conviene continuar inicialmente por la carretera que conduce hacía la población de Alcampell. Sin embargo, a la salida de Tamarite, nos convendrá tomar un camino por la izquierda (que pasa por las inmediaciones del Cementerio Municipal). Así, iniciaremos una hijuela de unos $5 \mathrm{Km}$, yendo hacía el Oeste. Por este camino, nos acercaremos al Estany de Queraltó. Al llegar a él efectuaremos una nueva parada, a unos $6 \mathrm{Km}$ escasos de la anterior.

En este recorrido, habremos ido encontrando afloramientos de los materiales citados en la parada anterior: los tramos de calcolutitas yesosas y yesos, pertenecientes a la Formación Barbastro, del Oligoceno. Por otra parte, en diversos lugares (como junto al Cementerio) habremos visto explotaciones abandonadas de los niveles yesosos.

Al llegar al lugar de la parada, nos encontraremos con una zona muy árida, con un interesante humedal. Se trata del Estany de Queraltó. Ahí efectuaremos una nueva parada, para observarlo de cerca.

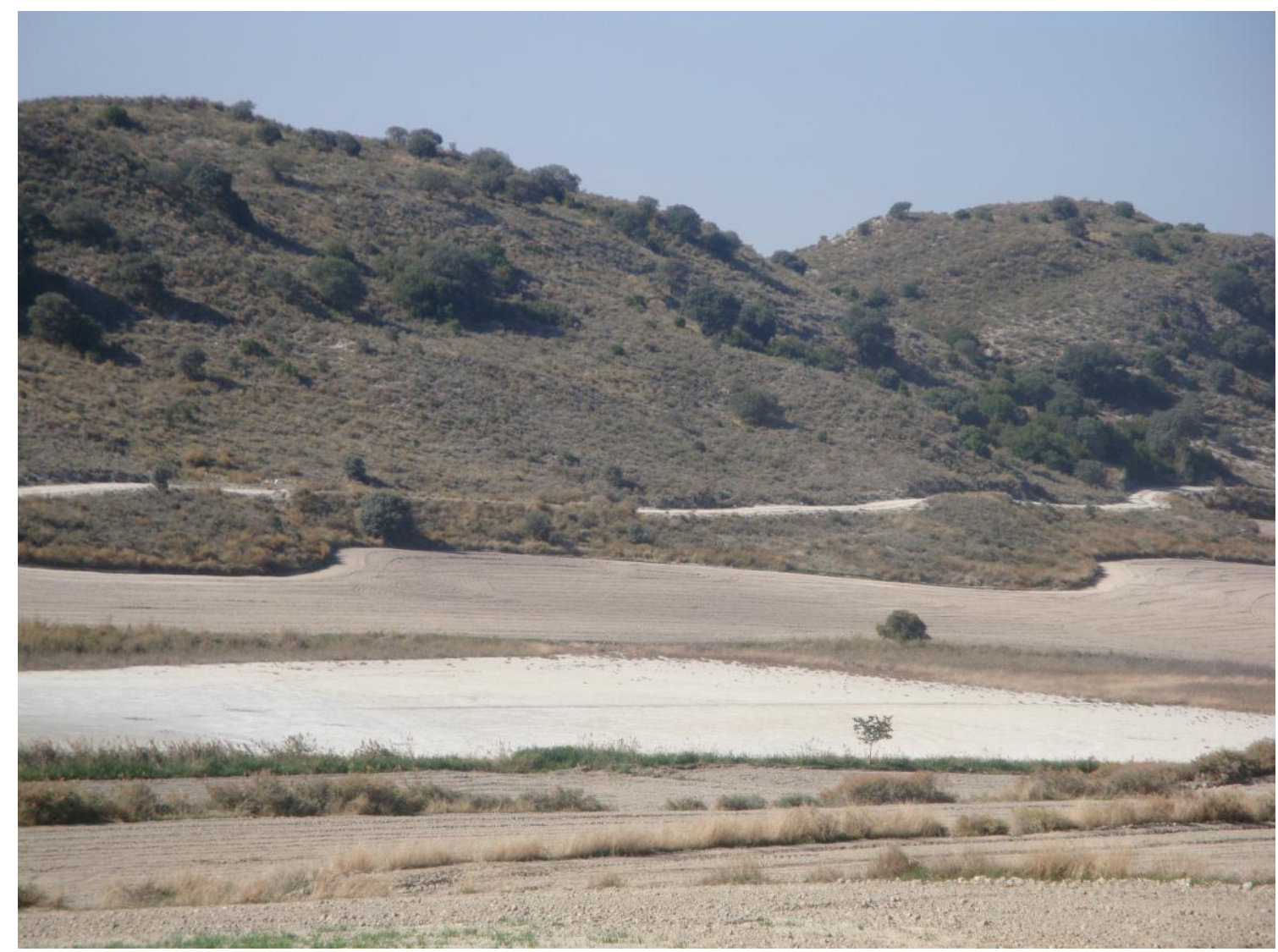

Estany de Queraltó 
Se trata de una laguna endorreica, Las aguas de la laguna son eminentemente salinas (ricas en halita y en sulfatos de calcio, magnesio sodio. y potasio), que al evaporarse el agua dejan un poso salino, unas eflorescencias blancas. Junto a la laguna hay una interesante vegetación de plantas adaptadas al medio salino. Cabe decir, finalmente que este lugar forma parte del Patrimonio Geológico de la comarca de la Litera.

PARADA 5. KARST DE YESOS DE ALCAMPELL, (término municipal de Alcampell, comarca de la Litera - Llitera). (Hoja 326).

Tras efectuar la parada anterior, conviene efectuar un nuevo recorrido, retornando a la carretera que conduce a Alcampell. Poco después de llegar a ella (a unos $3 \mathrm{Km}$ ) efectuaremos una nueva parada junto a la carretera. Así habremos recorrido unos $8 \mathrm{Km}$ desde la parada anterior.

En este recorrido, hemos ido encontrando los materiales yesosos citados en las paradas anteriores. Estos son los materiales que ahora están en la carretera, en el lugar de la parada. En este lugar puede observarse un interesante karst yesoso, que forma parte del Patrimonio Geológico de la comarca de la Litera.

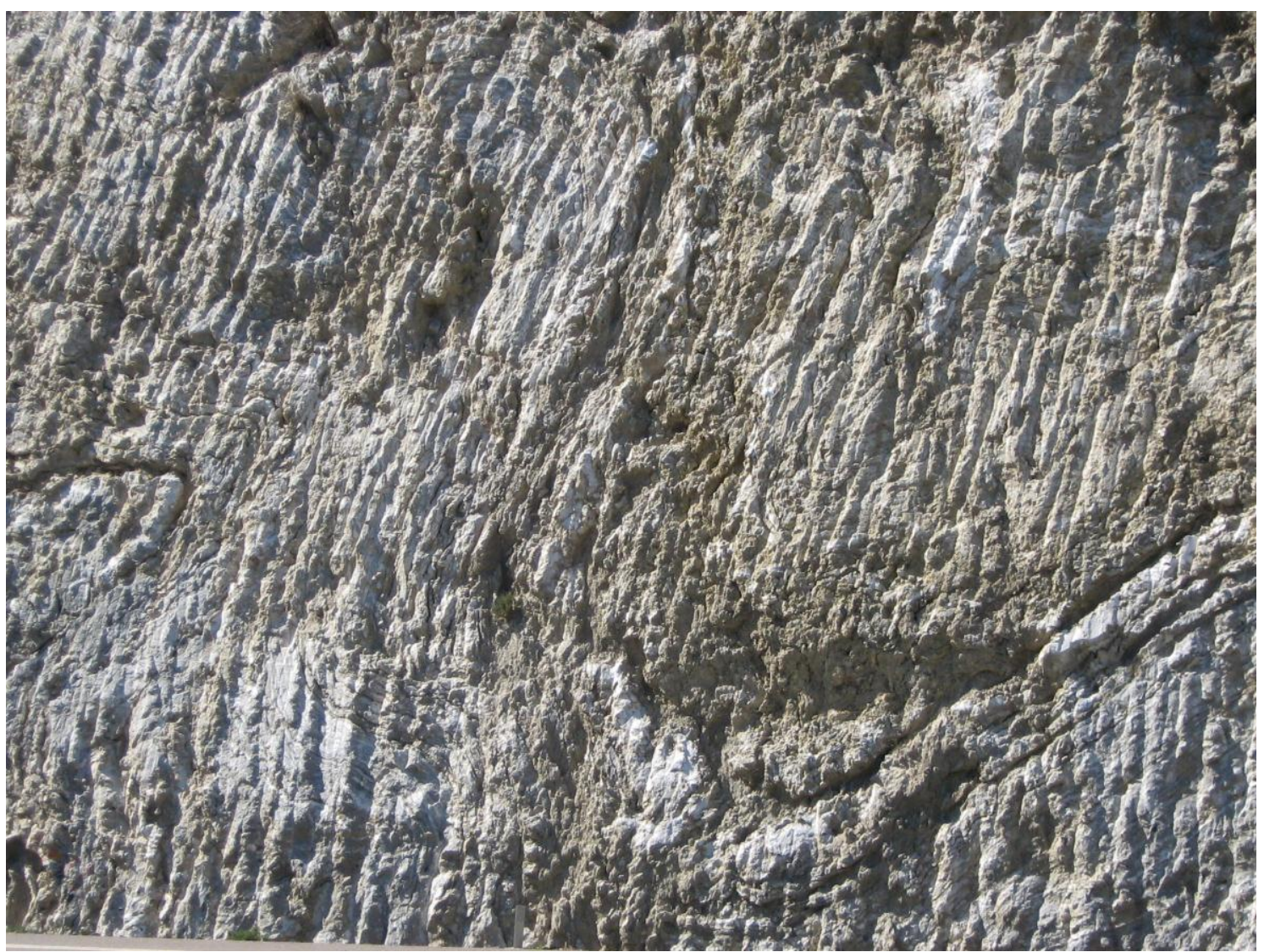

Aspecto de los yesos en la carretera de Tamarite de Litera a Alcampell 
PARADA 6. EL CASTILLOT, (término municipal de Baells, comarca de la Litera / Llitera). (Hoja 326).

Tras efectuar la parada anterior, conviene ahora llegar al pueblo de Alcampell, con la finalidad de seguir por la carretera hasta su entronque con la carretera nacional $\mathrm{N}-230$. Al llegar a ella, la tomaremos en sentido septentrional, hasta llegar al cruce de Baells. Tras encontrarlo, no dirigiremos al pueblo, continuando por el camino de Zurita. Sin embargo, a unos $3 \mathrm{Km}$ del pueblo encontraremos un camino hacía el Castillot, que ya habremos visto a lo largo del camino. Al llegar ahí efectuaremos una nueva parada, a unos $13-14 \mathrm{Km}$ de la anterior.

En este recorrido, habremos encontrado inicialmente afloramientos de los materiales yesosos citados en la parada anterior. Luego, por encima de estos, habremos visto importantes afloramientos de gravas cuaternarias.

Tras sobrepasar Baells, se habrán hecho evidentes los afloramientos de los materiales carbonatados cretácicos. Estos materiales forman parte de las Sierras Marginales Pirenaicas, en donde nos encontramos ahora. Precisamente, sobre estos materiales se ha desarrollado una interesante forma de erosión, que en la zona se denomina el Castillot.

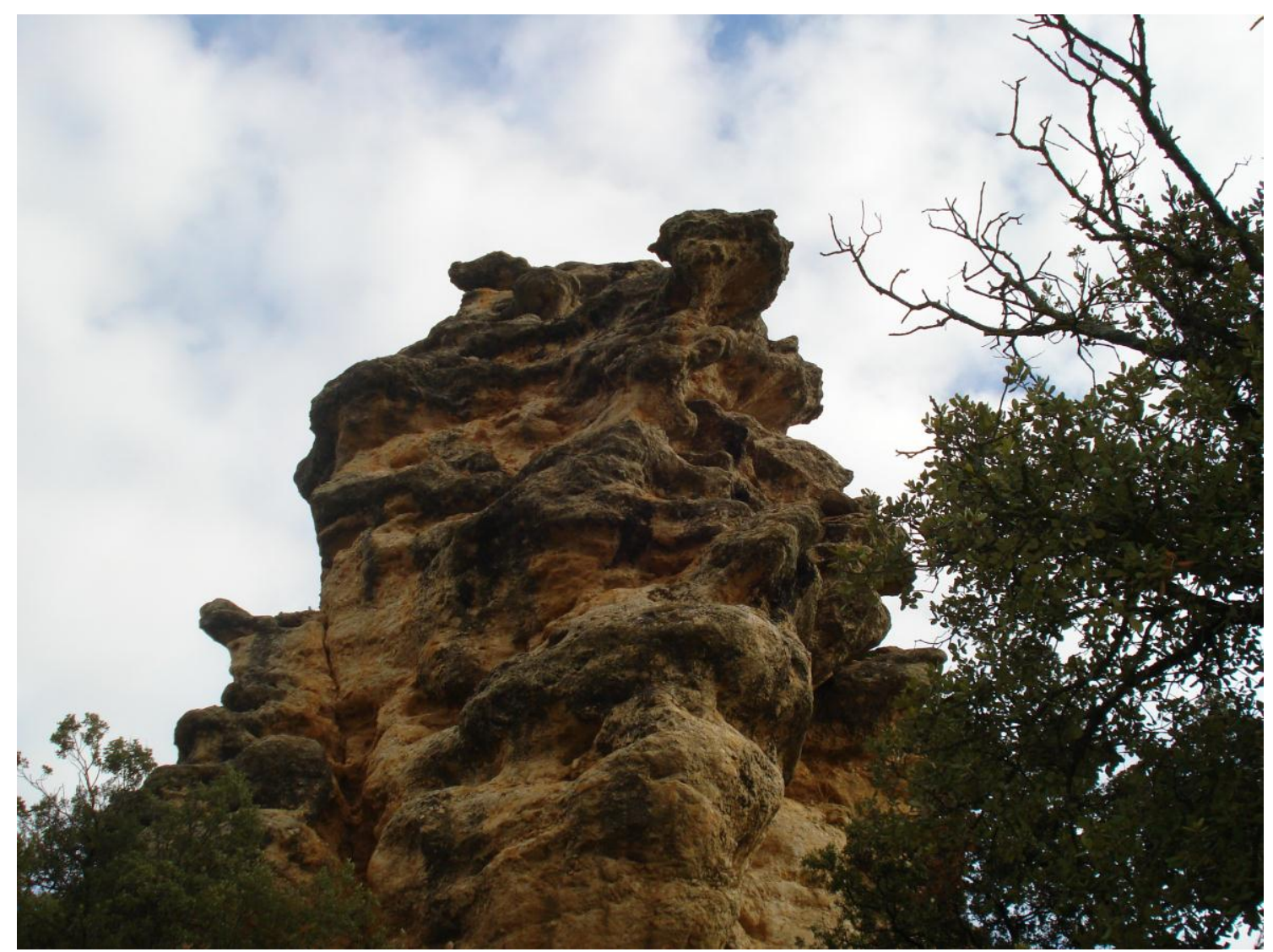

Un aspecto del Castillot

Cabe decir, que este lugar forma parte del Patrimonio Geológico de la comarca de la Litera 
PARADA 7. HORNO DE CAL DEL CASTILLOT, (término municipal de Baells, comarca de la Litera / Llitera). (Hoja 326).

Junto al Castillot, podemos hacer una nueva parada. Para ello, nos convendrá tomar una senda hacía el Este, llegando en unos 100 metros a un antiguo Horno de Cal.

En este breve recorrido, habremos encontrado los materiales citados en la parada anterior. Precisamente, estos materiales se han utilizado como materia prima para este horno de cal. Junto a él hay un plafón explicativo. Finalmente, conviene decir que este horno forma parte del Patrimonio Minero de la comarca de la Litera.

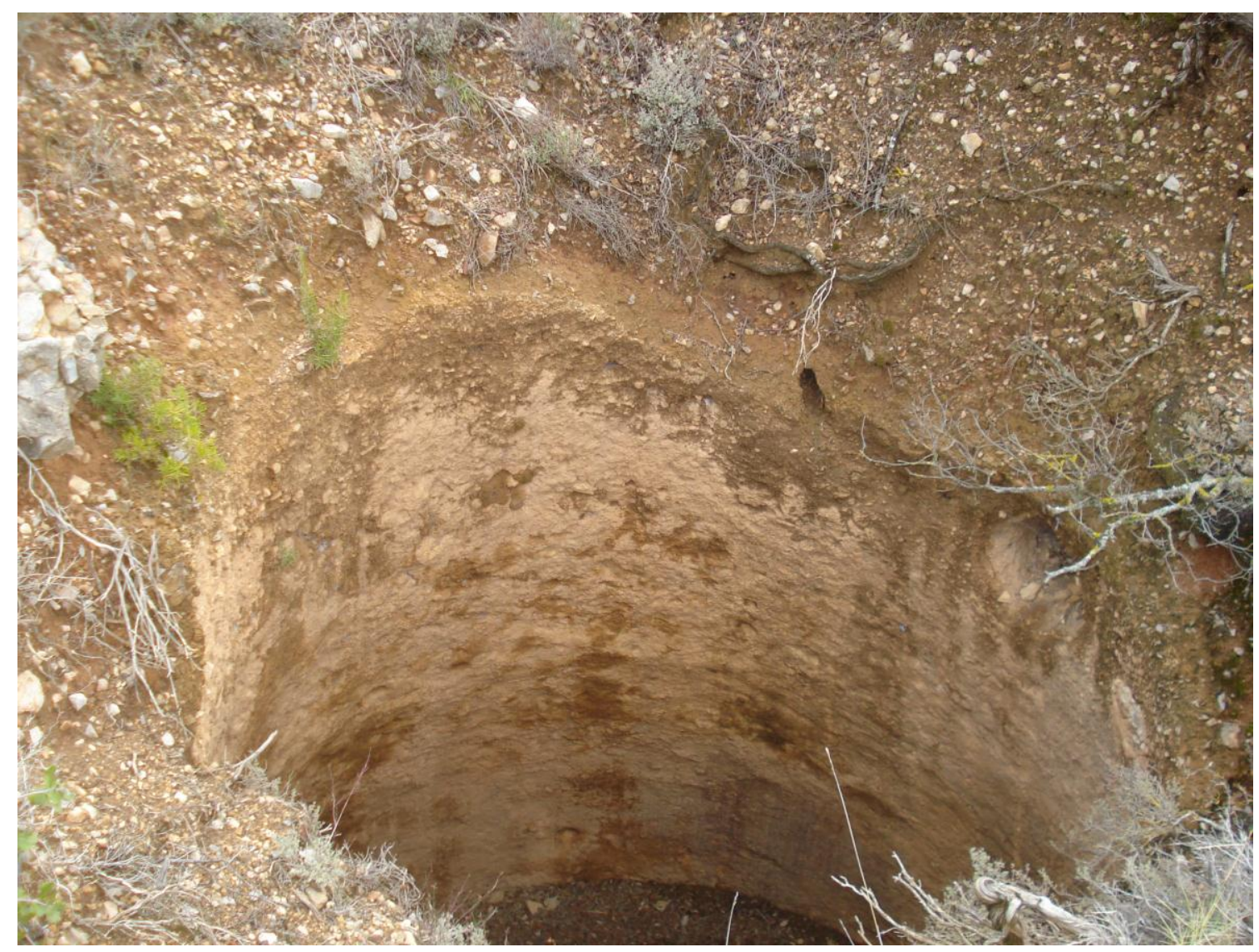

Restos del horno de cal

PARADA 8 - CONDICIONAL. CANTERA DE CALIZAS, (Nachá, término municipal de Baells, comarca de la Litera / Llitera). (Hoja 327).

Tras efectuar la parada anterior, conviene retornar a las inmediaciones de Baells, para ir luego hacía Nachá (utilizando en parte la carretera nacional N-230). Al llegar al pueblo, nos convendrá ir hacía una antigua cantera, situada en la parte septentrional del pueblo. Ahí, a unos $5 \mathrm{Km}$ de la parada anterior, podemos efectuar otra si se da el caso. 
En este recorrido, hemos encontrado lo materiales citados en la parada anterior, a menudo recubiertos por terrenos detríticos cuaternarios. Estos materiales carbonatados cretácicos son los que aparecen en el lugar de la parada, en donde han sido explotados en una antigua cantera, actualmente cerrada.

PARADA 9. LA MINA, (Nachá, término municipal de Baells, comarca de la Litera / Llitera). (Hoja 327).

Tras efectuar la parada anterior, conviene regresar al pueblo de Nachá, para tomar ahora la carretera que conduce a Camporrells. A la salida del pueblo, tras un descenso, encontraremos un barranco. Remontándolo llegaremos a un camino que conduce a la mina. Ésta se halla bajo el pueblo. Ahí efectuaremos la última parada del recorrido del itinerario, a unos $3 \mathrm{Km}$ de la anterior (uno en línea recta).

En este recorrido habremos ido encontrando afloramientos de los materiales carbonatados cretácicos; aunque bajo el pueblo y en barranco, habremos encontrado los materiales triásicos del Keuper (con abundantes yesos, arcillas y ofitas). Al llegar al lugar de la mina, habremos encontrado de nuevo los materiales carbonatados cretácicos

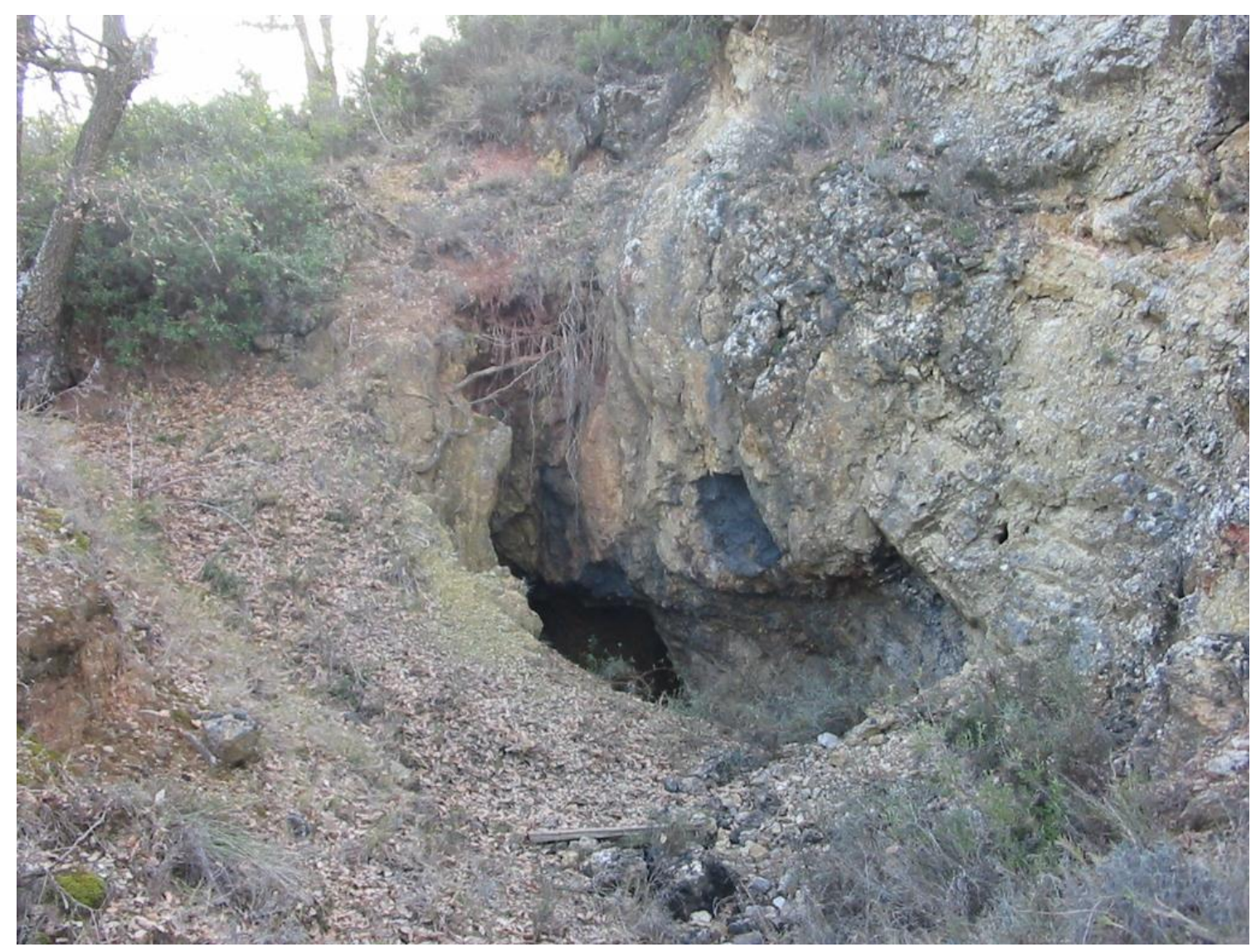

Un aspecto de las calizas, de la mina y de la mineralización

En ese lugar hay una interesante mineralización manganesífera de relleno de cavidades kársticas, situada entre las calizas cretácicas. Entre los minerales de manganeso presentes, cabe citar a los siguientes: PIROLUSITA, PSILOMELANA, 
RAMSDELLITA, TODOROGUITA, MANGANOCALCITA. Junto a ellos se encuentran también minerales de hierro, con: GOETHITA (limonita), HEMATITES. Asimismo, otro mineral presente es la CALCITA

Evidentemente, se trata de una mineralización muy importante, que puede ser considerada como un elemento importante del Patrimonio Geológico de la comarca de la Litera.

Finalmente, cabe decir que en el recorrido desde el pueblo, hemos atravesado el cabalgamiento de los materiales terciarios de la Depresión Geológica del Ebro, por parte de los del Pirineo. Este cabalgamiento se ha realizado gracias al carácter plástico de los materiales del Keuper que hemos visto anteriormente. (PARADA 8 BIS)

\section{EN ESTE LUGAR FINALIZA EL ITINERARIO}

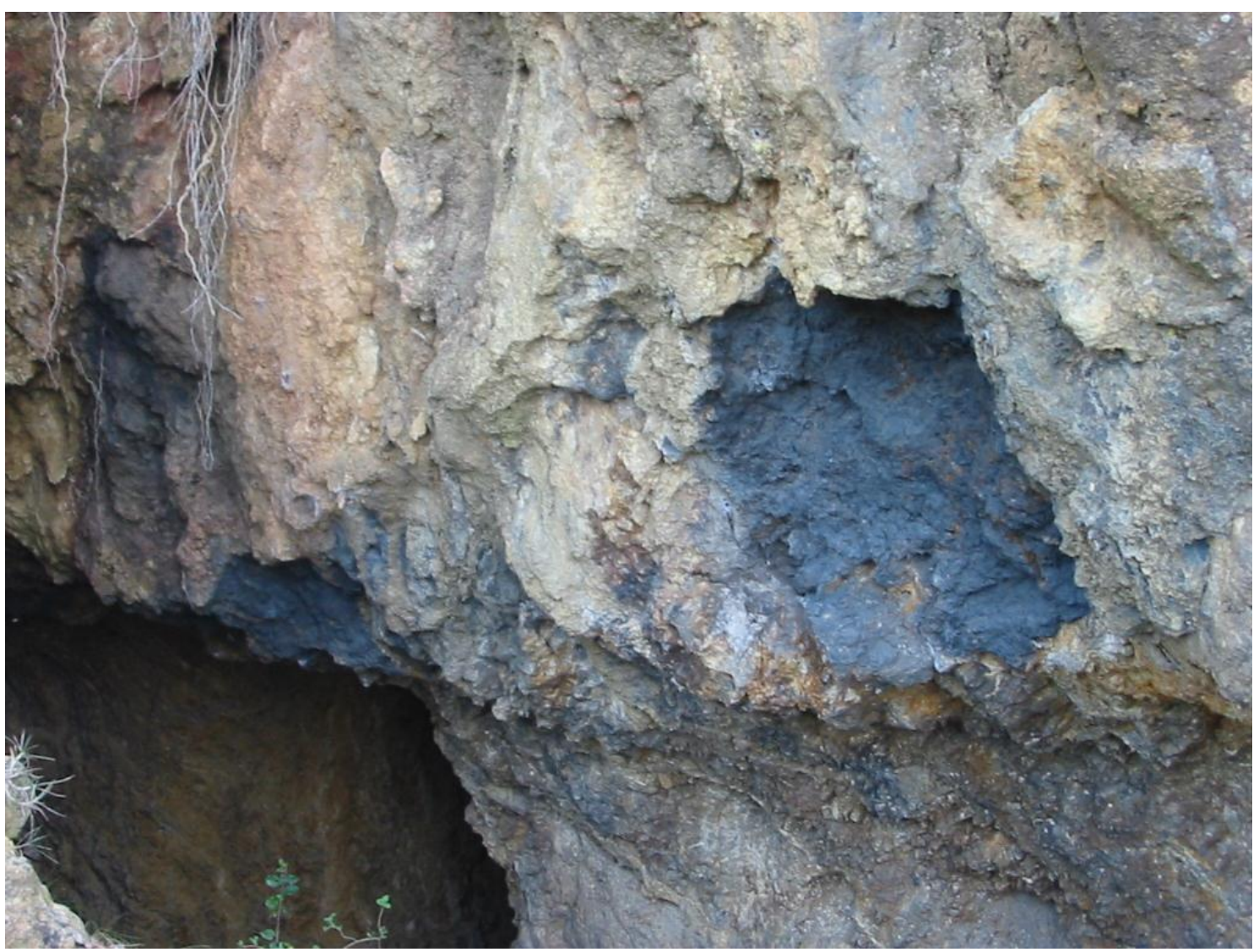

DETALLE DE LAS MINERALIZACIONES DE MANGANESO EN NACHÁ 


\section{BIBLIOGRAFÍA}

CALVO, M. et altri (1988).- Minerales de Aragón. Colección Temas geológicos. 200 pag. Zaragoza

GOBIERNO DE ARAGÓN (2001).- Puntos de Interés Geológico de Aragón. Consejería de Medio Ambiente del Gobierno de Aragón. Zaragoza

GUIMERÀ, J. et altri (1992).- Geología (II), Historia Natural de los Países Catalanes, Volum.2, 547 pag. Enciclopèdia Catalana, S.A. Barcelona

IGME (1972).- Mapa Geológico de España a escala 1:200.00 (Síntesis de la Cartografía existente). Hoja y memoria $n^{\circ} 23$ (Huesca). Inst. Geol. Min. España. Minist. Industria. Madrid

IGME (1974).- Mapa Metalogenético de España a escala 1:200.00. Hoja y memoria ${ }^{\circ}$ 23 (Huesca). Inst. Geol.Min. España. Minist. Industria. Madrid

IGME (1975).- Mapa de Rocas Industriales de España a escala 1:200.00. Hoja y memoria $n^{\circ} 23$ (Huesca). Inst. Geol.Min. España. Minist. Industria. Madrid

MAESTRE, A. (1845).- Visita al Distrito Minero de Aragón y Cataluña, Anales de Minas, tomo III, 145 pag. Madrid

MALLADA, L. (1881).- Descripción física y geológica de la provincia de Huesca.Mem. Com. Mapa Geol. De España. Vol. 15. pp. 1 - 439. Madrid

MATA - PERELLÓ, J.; (1987).- Introducción al conocimiento de las mineralizaciones aragonesas. Mineralogistes de Catalunya, t.III, pp. 258-265. Barcelona

MATA - PERELLÓ, J.M. (1990).- Inventario Mineralógico de la Región del Cinca (sectores Orientales). Rodeno, 19. 36 pag. Manresa

MATA-PERELLÓ, J.M. (1991).- Selección de Itinerarios de recerca mineralógica: por la Noguera, la Litera / Llitera i la Baja Ribagorza / Baixa Ribagorça. Xaragall, 27, 36 pag. Manresa

MATA-PERELLÓ, J.M. (1996).- Recerca geològica i mineralògica per les comarques del Segrià, Noguera, Litera / Llitera y Baja Ribagorza / Baixa Ribagorça: des d'Alfarràs a Peralta de la Sal, por Estopiñan / Estopanyà. Inédito, 10 pág. Manresa

MATA-PERELLÓ, J.M. (2002).- Recorregut de recerca geològica i mineralògica per les comarques del Segrià, de la Litera / Llitera i de la Baja Ribagorza / Baixa Ribagorça: des d'Alfarràs a Purroi y en Benabarre, revista Xaragall serie $\mathrm{B}, \mathrm{n}^{\mathbf{0}}$ 236, 12 pag. Manresa

MATA-PERELLÓ, J.M. i MONTANÉ GARCÍA. P. (2002).- Recorregut de recerca geològica i mineralògica per les comarques del Segrià, la Litera / Llitera i la Baja 
Ribagorza / Baixa Ribagorça: des d'Alfarràs a Camporrells, a Caladrones / Caladrons i a Benabarre, Inédito, 14 pag. Manresa

MATA-PERELLÓ, J.M. i MONTANÉ GARCÍA. P. (2004).- Recorregut de recerca geològica i mineralògica per les comarques del Segrià, la Litera / Llitera i la Baja Ribagorza / Baixa Ribagorça: des d'Alfarràs a Estopiñan / Estopanyà i a Benabarre, Inédito, 14 pag. Manresa

MATA-PERELLÓ, J.M. i SANZ BALAGUÉ, J. (1989).- Inventari Mineralògic de la comarca de la Litera / Llitera. Revista Tierra Endins, nº 2, 32 pag. Manresa

PRAMES (2005).- Campo de Belchite. Colección RUTASCAL por Aragón. Prames, Gobierno de Aragón. 119 pag. Zaragoza.

RIBA, O. et altri (1976).- Geografía Física de los Países Catalanes, Edit. Ketres, 254 páginas. Barcelona 